\title{
Domestic Burglaries and the Real Price of Audio-visual Goods: Some Time Series Evidence for Britain
}

\begin{abstract}
This paper explores the relationship between the real price of audio-visual goods and domestic burglaries using British data. Our findings suggest that the falling real price of these consumer goods has contributed to a reduction in domestic burglary activity.
\end{abstract}

\author{
Barry Reilly \\ Department of Economics \\ University of Sussex \\ Brighton \\ BN1 9QN \\ United Kingdom
}

JEL: J6 K14

*Corresponding Author

\author{
Robert Witt* \\ Department of Economics \\ University of Surrey \\ Guildford \\ GU2 7XH \\ United Kingdom \\ e-mail: r.witt@surrey.ac.uk \\ Tel: +44-1483-686954 \\ Fax: +44-1483-689548
}

Keywords: Burglary Audio-visual Goods' Prices Cointegration 


\section{Introduction}

There is a well established empirical literature that explores for Great Britain the nature of the relationship between acquisitive criminal behavior and economic activity. This literature includes studies that investigate the correlations between various crime types and unemployment (e.g., Reilly and Witt 1996, Carmichael and Ward 2001), and changes in labor market conditions as measured by earnings inequality (e.g., Witt et al. 1998, Machin and Meghir 2004).

The recent and dramatic fall in UK domestic burglary is a well documented phenomenon but one for which a fully convincing explanation has yet to be provided. The British Crime Survey (BCS) and police recorded crime data reveal sharp falls in burglary levels since peaks in the early/mid 1990s (see Walker et al. 2006). The number of domestic burglaries recorded by the police fell by nine percent between 1998/9 and 2001/2, and there were further falls of close to one-third between 2002/3 and 2005/6 (Walker et al. 2006).

Some recently published descriptive analysis, using recorded domestic burglary data in an area of the West Midlands in England, argues that the primary reason for the observed fall in burglaries involving the theft of audio-visual equipment is the lower prices that such goods command in the illegal market (see Wellsmith and Burrell 2005). In this short paper we evaluate this proposition by investigating the relationship between domestic burglary and the real retail price of audio-visual goods using annual time series data.

\section{Data and Empirical Methodology}

We posit a simple empirical model that relates domestic burglaries to two measures of social and/or economic disadvantage and a real price variable that acts as a proxy for the incentive to commit a burglary. Given data constraints, potentially relevant judicial deterrent measures are unavailable and so do not feature in our analysis. Thus, the variables used comprise of annual time series data for domestic burglary (B), the 
unemployment rate (UR), a Gini coefficient measuring household income inequality (GINI), and the real retail price of audio-visual equipment (P). We confine our empirical analysis to the time period covering 1976 to 2005, given that the price index for audiovisual equipment is only available on a consistent basis from 1974 onwards. ${ }^{1}$ A more detailed description of the data used is found in table 1.

\section{Table 1 about here}

The time series properties of both the levels and differenced series are interrogated more thoroughly in the next section using formal testing procedures. As a prelude, we initially review the plots for the relevant series. The series expressed in levels (see Figure 1) reveal little evidence of mean reversion in contrast to those depicting the differenced series (see Figure 2). In order to obtain some insights on the levels' relationship over time between domestic burglary and the other three series, standardized pair-wise plots are also reported in figure $3 .^{2}$ This figure reveals a very tight positive relationship between domestic burglary and the unemployment rate over time, and a positive association between domestic burglary and the inequality measure over the earlier phases of the time period. The well documented decline in the former appears to occur when the change in the inequality measure flattens out. The relationship between burglaries and the retail price series provides a more mixed picture with the latter variable exhibiting a strong and persistent downward movement over time which eventually matches the downward movement in domestic burglary. ${ }^{3}$

An unrestricted error correction mechanism (ECM) framework is exploited to model domestic burglaries. This approach provides, among other things, an econometrically efficient basis to test for cointegration between the variables of interest. In terms of the

\footnotetext{
1 The retail price indices for 'all items' and the audio-visual equipment are both based at January 1974=100. Thus, use of the initial annual observation in the empirical analysis provides little information on relative price movements. In addition, since lagged values of the relative log price variable are used, it was deemed prudent to commence the regression analysis from 1976.

${ }^{2}$ The series in levels are standardized by subtracting the mean and dividing by the standard deviation of the relevant series.

${ }^{3}$ The real retail price of audio-visual equipment fell by an average 10 percent per annum between 1976 and 2005.
} 
dynamic modelling, we believe it relatively innocuous to assume that the unemployment rate, income inequality, and the logarithm of the real price of audio-visual goods are all weakly exogenous with respect to the logarithm of domestic burglaries. The two variables capturing economic and/or social disadvantage enter the specification in nonlogged form as model selection criteria (i.e., the Akaike Information Criterion and the Schwartz Bayesian Criterion) were found to favour the econometric model containing this formulation over an alternative that used their logarithmic forms.

\section{Empirical Results}

The unit root tests for the individual series are reported in table 2 with results sensitive to whether the Dickey-Fuller (DF) or augmented Dickey-Fuller (ADF) tests are used. In a number of cases two lag orders of the dependent variable are required to clean the residuals in the ADF regression model. In general, the tests reveal that the levels' series are interpretable as integrated of order one (i.e., I(1)), and the differenced measures of order zero (i.e., I(0)). Though comforting, the unit root test results should be treated as suggestive given our econometric modelling approach does not require pre-testing of the individual series to determine their order of integration and, moreover, can be implemented irrespective of whether the underlying variables are I(0), I(1) or even fractionally integrated processes. In addition, two of the variables used, the unemployment rate and the Gini, are bounded from above and their evolution in an unbounded manner is thus implausible. However, the realizations for both variables in this application are well below their upper boundaries, so this is not viewed as a serious issue that impacts on the econometric modeling.

\section{Table 2 about here}

The econometric results for our favoured model are reported in table 3 . The value of the goodness-of-fit measure is more than adequate, and the reported diagnostics confirm the estimated regression model satisfies standard OLS assumptions. The CUSUM and 
CUSUMSQ plots (not reported) respectively reveal no evidence of random or systematic movements in the estimated coefficients over the estimation period.

The short-run effects for the real audio-visual price variable and the Gini measure are poorly determined, but the unemployment rate yields a precisely estimated positive effect. Using the pseudo F-test suggested by Pesaran and Pesaran (1997, pp.302-308), the null hypothesis of non-cointegration is decisively rejected by the data with a high level of confidence. There is thus persuasive evidence that the logarithm of domestic burglaries, the unemployment rate, income inequality, and the logarithm of the real price of audiovisual equipment comprise a set of cointegrated variables that have broadly moved together over the long-run sample period. The speed of adjustment is estimated to be fairly rapid and suggests that about one-half of any disequilibrium induced by a shock to the long-run steady state relationship is eliminated within one year.

The static long-run estimates for the steady-state relationship are computed from the unrestricted ECM model in table 3 as:

$$
\begin{aligned}
\log _{\mathrm{e}}(\mathrm{B})^{*}= & 9.651+0.079 \mathrm{UR}^{*}+0.286 \log _{\mathrm{e}}(\mathrm{P})^{*}+10.63 \mathrm{GINI} \mathrm{I}^{*} \\
& (0.471)(0.011)
\end{aligned}
$$

where * here denotes steady-state values and the standard errors, calculated using the delta method, are reported in parentheses. All the estimated long-run effects are found to be well determined. Both measures of disadvantage exert positive effects on the volume of domestic burglary. The semi-elasticity estimates suggests that a one percentage point rise in the unemployment rate raises domestic burglary in the long-run by 7.9 percent, on average and ceteris paribus, while a similar rise in the Gini raises domestic burglary by 10.6 percent. The point estimates for the implicit long-run elasticities, computed using the sample average means for these two variables, are 0.49 and 3.29 for the unemployment rate and the Gini respectively. The latter result suggests that domestic 
burglaries are highly elastic with respect to movements in income inequality. ${ }^{4}$ A key finding of our empirical work, however, is the positive and well determined long-run relationship between domestic burglary and the real retail price of audio-visual goods. The long-run response is found to be relatively inelastic with a 10 percent fall in the real retail price of audio-visual equipment reducing the volume of domestic burglary by a modest 2.9 percent in the long-run, on average and ceteris paribus. ${ }^{5}$

\section{Table 3 about here}

\section{Conclusions}

The empirical results reported in this short paper confirm the unemployment rate as an important and robust factor (both in the short- and long-run) in explaining domestic burglary in England and Wales. The model estimates also highlight a key role in the long-run for income inequality and suggest domestic burglaries are extremely sensitive to movements in this measure. The novel contribution of this paper lies in the exploration of the role played by the real price of audio-visual goods. Our findings suggest that the falling real price of these goods over the last two decades has contributed to a reduction in the volume of domestic burglary activity in England and Wales. The inelastic magnitude of the effect perhaps suggests a modest contribution for this particular factor, though it should be noted that the decrease in real prices has been substantial over the relevant time period. The fact that falling real prices of such goods exert a negative impact on domestic burglary activity could be interpreted by some as a socially useful benefit of globalization. However, the well documented fall in activity within this category in recent times potentially conceals a displacement effect with criminals, in all likelihood, substituting into other illegal and more lucrative alternatives.

\footnotetext{
${ }^{4}$ The estimated sign for this long-run effect is consistent with the theorizing offered by Chiu and Madden (1998).

${ }^{5}$ The regression model was augmented by the inclusion of a deterministic time trend variable. Although the estimated effects for the other long-run variables retained their individual statistical significance (and the point estimate for the price effect rose), the estimated coefficient for the trend variable attracted a t-ratio of about 1.5 .
} 
It should be emphasized that our analysis is supported by a mere 30 years of annual data and our findings may prove to be both time period and country specific. Although our favored model performs well within-sample in terms of the reported diagnostic tests, it may provide poor out-of-sample predictive power in an environment where the nature of criminal activity in Britain is rapidly changing.

\section{Appendix}
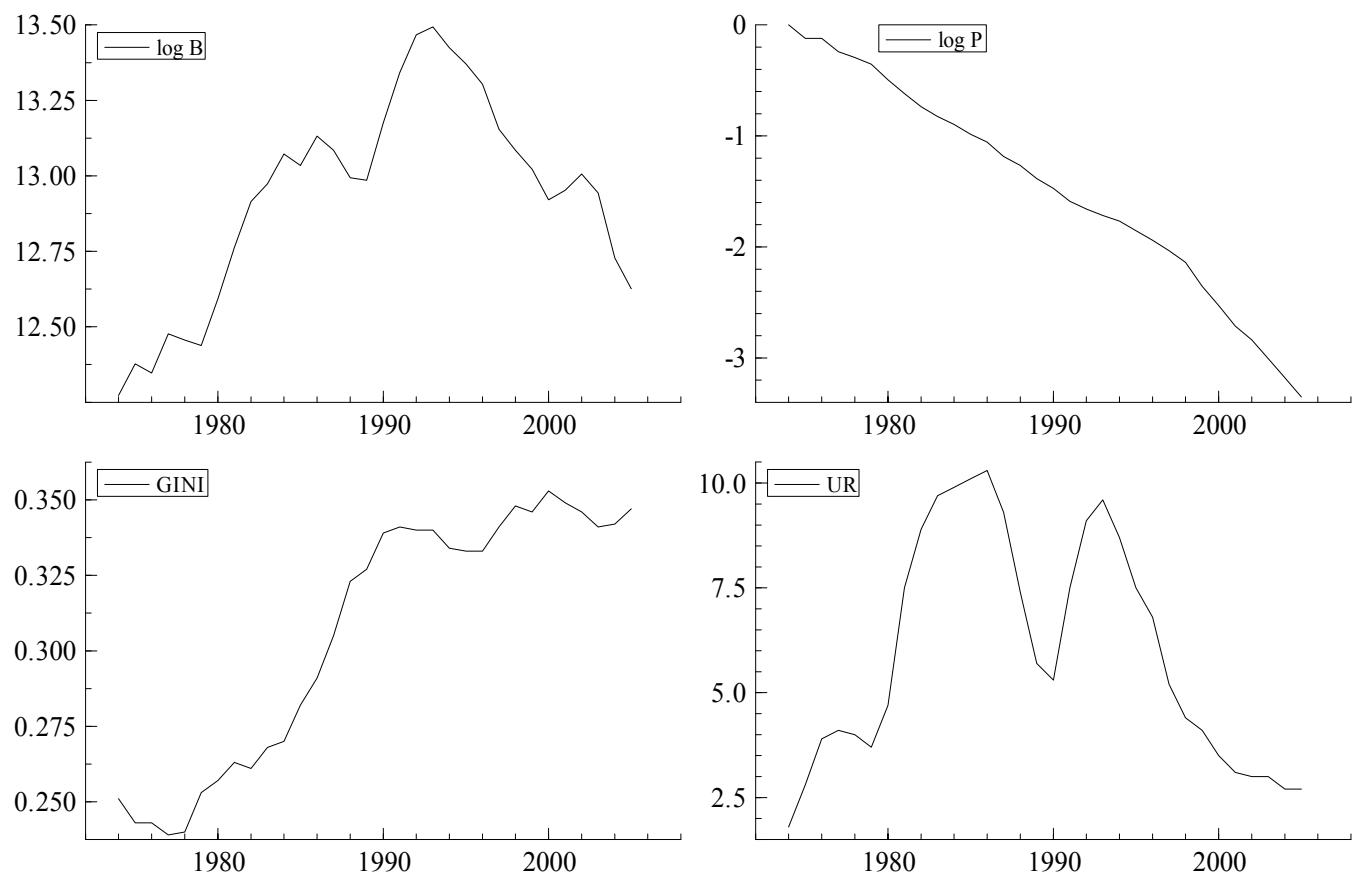

Figure 1.Burglary Series and Economic Variables 

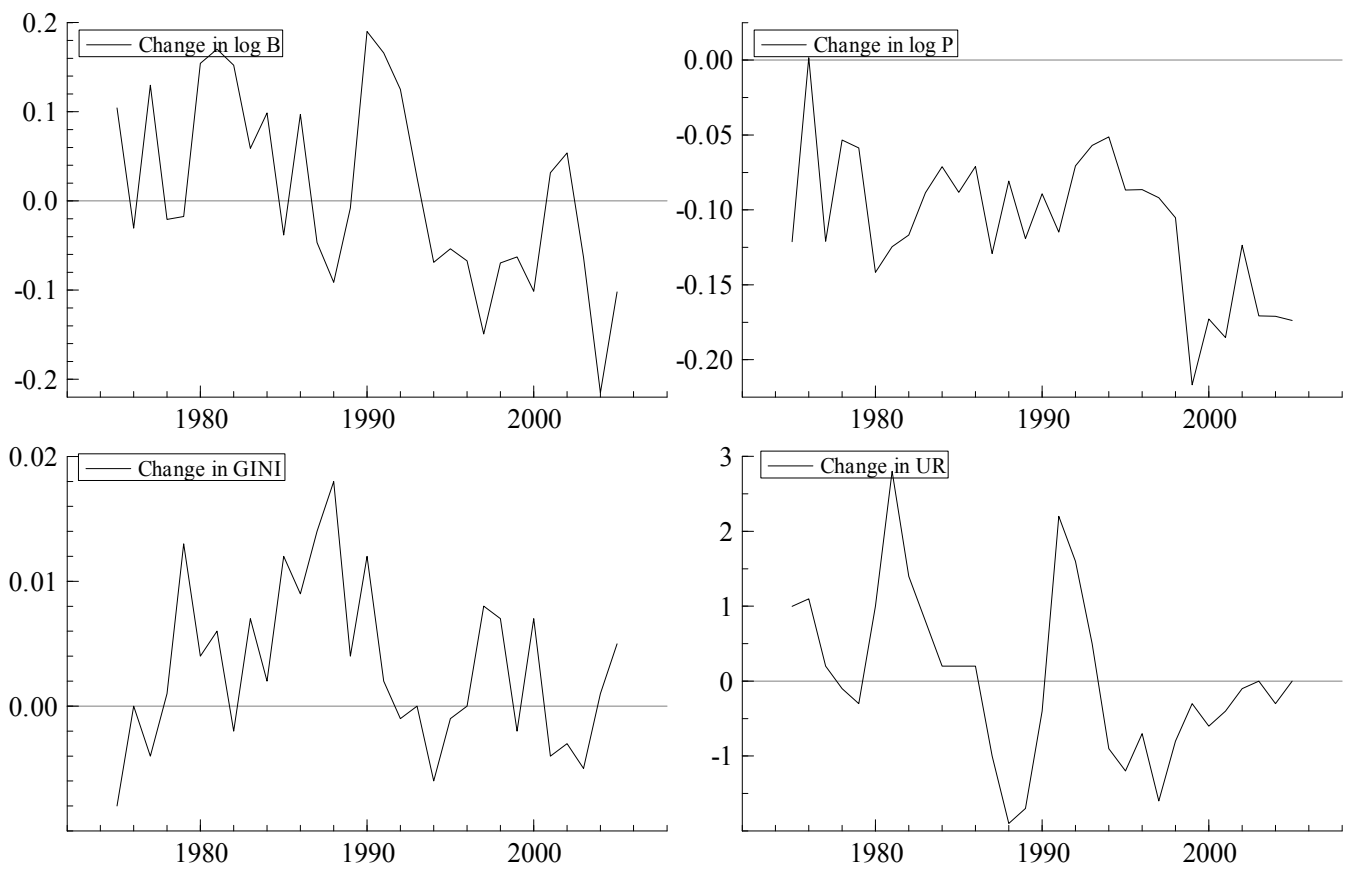

Figure 2: Changes in Burglary Series and Economic Variables 

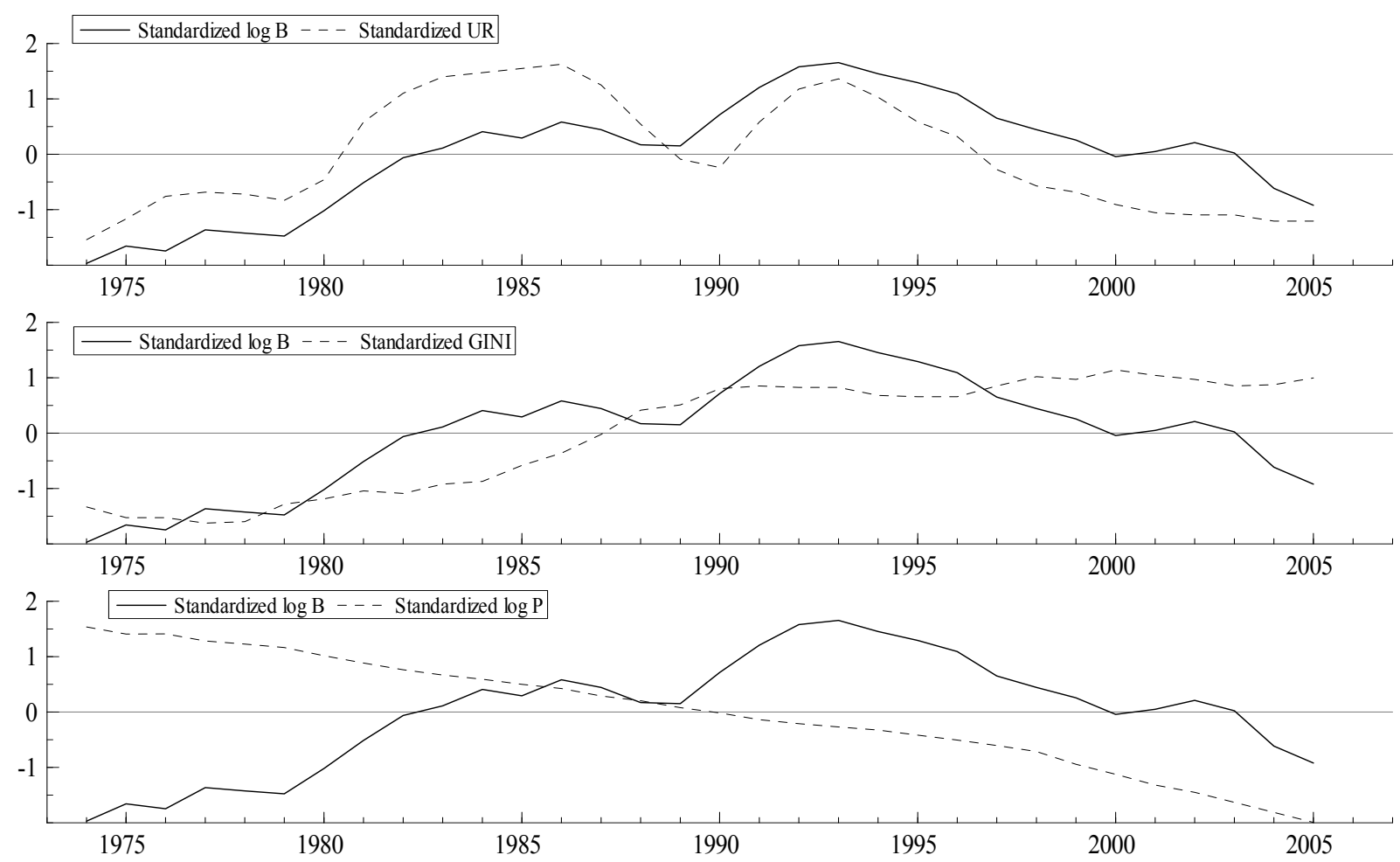

Figure 3. Standardized Deviations in Burglary Series and Economic Variables

\section{References}

Carmichael, F. and R. Ward, 2001, Male unemployment and crime in England and Wales, Economics Letters 73, 111-115.

Chiu, W.H. and P. Madden, 1998, Burglary and income inequality, Journal of Public Economics 69, 123-141.

Machin, S. and C. Meghir, 2004, Crime and economic incentives, Journal of Human Resources, 39, 958-979.

Pesaran, M. H. and B. Pesaran, 1997, Working with Microfit 4.0 Interactive Econometric Analysis (Oxford University Press).

Reilly, B. and R. Witt, 1996, Crime, deterrence and unemployment in England and Wales: an empirical analysis, Bulletin of Economic Research, 48, 137-159.

Walker, A., C. Kershaw and S. Nicholas, 2006, Crime in England and Wales 2005/06, Home Office Statistical Bulletin 12/06.

Wellsmith, M. and A. Burrell, 2005, The influence of purchase price and ownership levels on theft targets, British Journal of Criminology, 45, 741-764. 
Witt, R., A. Clarke, and N. Fielding, 1998, Crime, Earnings Inequality and Unemployment in England and Wales, Applied Economics Letters, 5, 265-267.

\section{Table 1: Variable Description}

\begin{tabular}{l|l}
\hline Variable & Description \\
\hline B & $\begin{array}{l}\text { Burglary in a dwelling (i.e., domestic burglary) for England and } \\
\text { Wales as recorded by the relevant police force: Source - Home } \\
\text { Office. }\end{array}$ \\
\hline UR & $\begin{array}{l}\text { The Total Unemployment Rate (expressed in percentages) based on } \\
\text { the claimant count for Great Britain : Source - NS online MDS. }\end{array}$ \\
\hline GINI & $\begin{array}{l}\text { The Gini Coefficient (expressed fractionally) before Housing Costs } \\
\text { (from 1993-94 financial years) for Great Britain: Source - Institute } \\
\text { of Fiscal Studies (IFS). }\end{array}$ \\
\hline P & $\begin{array}{l}\text { The ratio of the audio-visual equipment retail price index price to } \\
\text { the all items retail price index (based January 1974=100) for the } \\
\text { United Kingdom: Source - Institute of Fiscal Studies (IFS). }\end{array}$ \\
\hline
\end{tabular}

Table 2: Unit Root Tests

\begin{tabular}{l|l|l}
\hline & Dickey-Fuller Test & $\begin{array}{l}\text { Augmented Dickey } \\
\text { Fuller Test }\end{array}$ \\
\hline $\log _{\mathrm{e}}(\mathrm{B})_{\mathrm{t}}$ & 0.140 & $-0.517^{f}(\mathrm{ADF}(1))$ \\
\hline $\log _{\mathrm{e}}(\mathrm{P})_{\mathrm{t}}$ & 0.663 & $-0.307^{f}(\mathrm{ADF}(2))$ \\
\hline $\mathrm{UR}_{\mathrm{t}}$ & -1.686 & $-1.574^{f}(\mathrm{ADF}(2))$ \\
\hline $\mathrm{GINI}_{\mathrm{t}}$ & -0.397 & $-2.075^{f}(\mathrm{ADF}(2))$ \\
\hline$\Delta_{1} \log _{\mathrm{e}}(\mathrm{B})_{\mathrm{t}}$ & $-3.669^{f}$ & $-3.629(\mathrm{ADF}(1))$ \\
\hline$\Delta_{1} \log _{\mathrm{e}}(\mathrm{P})_{\mathrm{t}}$ & $-4.517^{f}$ & $-2.169(\mathrm{ADF}(1))$ \\
\hline$\Delta_{1} \mathrm{UR}_{\mathrm{t}}$ & -2.631 & $-4.215^{f}(\mathrm{ADF}(1))$ \\
\hline$\Delta_{1} \mathrm{GINI}_{\mathrm{t}}$ & $-4.016^{f}$ & $-2.767(\mathrm{ADF}(1))$ \\
\hline
\end{tabular}

Notes to table 2:
(a) $\quad \Delta_{1}$ and $\log _{\mathrm{e}}(\cdot)$ denote the first difference and natural log operator respectively;
(b) The critical value at the 0.05 level for the unit root tests is -3.57 ;
(c) regression models include constant and deterministic trend and the ADF contains either one or two lags of the dependent variable (see above);

(d) $\quad f$ denotes preferred test value given clean diagnostics in the regression models;

(e) time period for unit root tests:1976 to 2005 . 
Table 3: Unrestricted ECM Model for Domestic Burglary Activity

\begin{tabular}{|c|c|}
\hline Variable & $\begin{array}{l}\text { Estimated OLS } \\
\text { Coefficients }\end{array}$ \\
\hline Constant & $\begin{array}{l}4.602^{*} \\
(2.193)\end{array}$ \\
\hline$\Delta_{1} \mathrm{UR}_{\mathrm{t}}$ & $\begin{array}{l}0.062 * * \\
(0.012)\end{array}$ \\
\hline$\Delta_{1} \log _{\mathrm{e}}(\mathrm{P})_{\mathrm{t}}$ & $\begin{array}{l}-0.067 \\
(0.342)\end{array}$ \\
\hline$\Delta_{1} \mathrm{GINI}_{\mathrm{t}}$ & $\begin{array}{l}-1.497 \\
(2.072)\end{array}$ \\
\hline $\log _{\mathrm{e}}(\mathrm{B})_{\mathrm{t}-1}$ & $\begin{array}{l}-0.477 * * \\
(0.156)\end{array}$ \\
\hline $\mathrm{UR}_{\mathrm{t}-1}$ & $\begin{array}{l}0.038^{* *} \\
(0.013)\end{array}$ \\
\hline $\log _{\mathrm{e}}(\mathrm{P})_{\mathrm{t}-1}$ & $\begin{array}{l}0.137 * * \\
(0.036)\end{array}$ \\
\hline $\mathrm{GINI}_{\mathrm{t}-1}$ & $\begin{array}{l}5.069 * * \\
(1.254)\end{array}$ \\
\hline Adjusted-R ${ }^{2}$ & 0.685 \\
\hline$\hat{\sigma}$ & 0.059 \\
\hline Time Period & 1976 to 2005 \\
\hline Number of Annual Observations & 30 \\
\hline \multicolumn{2}{|l|}{ Diagnostic Tests: } \\
\hline $\begin{array}{l}\text { Breusch-Godfrey Test for Serial Independence of } \\
\text { Residuals } \sim \chi_{1}^{2}\end{array}$ & $\begin{array}{c}0.000 \\
{[0.996]}\end{array}$ \\
\hline Ramsey's RESET $\sim \chi_{1}^{2}$ & $\begin{array}{c}0.065 \\
{[0.789]}\end{array}$ \\
\hline Bera-Jarque Normality Test $\sim \chi_{2}^{2}$ & $\begin{array}{c}1.135 \\
{[0.567]}\end{array}$ \\
\hline Homoscedasticity Test $\sim \chi_{1}^{2}$ & $\begin{array}{c}1.012 \\
{[0.314]}\end{array}$ \\
\hline $\begin{array}{l}\text { Autoregressive Conditional Heteroscedasticity } \\
\text { Test } \sim \chi_{1}^{2}\end{array}$ & $\begin{array}{c}0.208 \\
{[0.648]}\end{array}$ \\
\hline $\begin{array}{l}\text { Pesaran \& Pesaran Pseudo-F test for } \\
\text { Cointegration }\end{array}$ & $6.818 * *$ \\
\hline
\end{tabular}

Notes to table 3:

(a) $\quad \Delta_{1}$ and $\log _{\mathrm{e}}(\cdot)$ denote the first difference and natural log operator respectively;

(b) the dependent variable is $\Delta_{l} \log (\mathrm{B})_{\mathrm{t}}$;

(c) OLS standard errors are reported in parentheses for coefficient estimates;

(d) $\quad * *$ and $*$ denote statistical significance at the 0.01 and 0.05 level respectively using twotailed tests;

(e) prob-values are reported in parentheses for the diagnostic tests.

(f) The relevant critical values for the cointegration test is: $F_{\text {lower }}=5.315 \& F_{\text {upper }}=6.414$ at the $99 \%$ confidence level. 